\title{
MIMO INTELLIGENT-PID CONTROLLER DESIGN FOR HALF CAR SYSTEM BASED ON MODEL FREE CONTROL TECHNIQUE
}

\author{
Fathi Djemal, Maroua Haddar \\ Laboratory of Mechanics, Modelling and Production (LA2MP), National School of Engineering of Sfax, \\ University of Sfax, Tunisia \\ e-mail: fathidjemal@yahoo.fr; haddar.marwagem1@gmail.com \\ S. CAglar Baslamisli \\ Hacettepe University Beytepe, Department of Mechanical Engineering, Ankara, Turkey \\ e-mail: caglar.baslamisli@gmail.com \\ Riadh Chatri, Fakher Chaari, Mohamed Haddar \\ Laboratory of Mechanics, Modelling and Production (LA2MP), National School of Engineering of Sfax, \\ University of Sfax, Tunisia \\ e-mail:rchaari@yahoo.fr; fakher.chaari@gmail.com; mohamed.haddar@enis.rnu.tn
}

\begin{abstract}
A novel decoupled Multi-Input-Multi-Output Model Free Control strategy is presented in this paper to improve the performance of an active suspension system implemented on a half car model. To damp vibrations generated by road excitation, an algebraic online compensator was integrated in the structure of a classical PID controller to avoid the impact of unpredictable disturbances. The key element of the proposed technique is a non-asymptotic observer that can avoid the use of statistical conventional techniques. Furthermore, the advantage of easy implementation is achieved where only two accelerometers are sufficient and adequate. A comparison with classical PID and LQR is provided to demonstrate the improvement made by the proposed scheme.
\end{abstract}

Keywords: Model Free Control, intelligent-PID controller, ultra-local model, on-line observer

\section{Introduction}

Following the development of technology, the automotive field is increasingly concentrating on improving vehicle ride comfort and security. Basically, a suspension system has the fundamental role to guarantee required comfort while avoiding road shocks from the cabin. Therefore, researchers have developed several types of suspension systems with integrated methods for controlling manoeuvrability of the car in real driving conditions. Those strategies can be divided into three groups: passive, semi-active (Maciejewski et al., 2019) and active approaches (Euczko and Ferdek, 2016), which is the most used (Rajamani, 2011).

Active suspensions provide an additive actuating force integrated in the closed loop control. The control power depends greatly on the choice of appropriate control schemes. Recently, many advanced active control strategies were developed by using different kinds of control techniques such as Linear Quadratic Regulator (LQR) (Ferdek and Łuczko, 2015), adaptive control (Hua et al., 2018), fuzzy control (Senthil Kumar et al., 2018), neural network control (Phu et al., 2018) and linear tracking control based on a high gain observer (Hasbullah and Faris, 2017). Particularly, Model Free Control (MFC) (Fliess and Join, 2013) is an effective technique to realize multi-objective and modifications in the feedback control and estimation process. In recent years, this strategy has been applied in several fields. The power of the intelligent controller resides in estimating on-line perturbations without the need of a classical state observer such as Kalman 
filter. The method is easily implemented and avoids the difficult task of coefficient tuning. Only the knowledge of the input-output behaviour of the plant is needed for updating the controller parameters automatically.

The present work is based on the theory of intelligent controllers which are proposed by Fliess and Join (2013). Several studies were carried to integrate this control method to a quarter car model which is a two degree of freedom vehicle ride model. For example, a novel intelligent-PD controller for the quarter car model was proposed by Haddar et al. (2019b). Furthermore, Haddar et al. (2017) suggested a method for classical Active Disturbances Rejection Control (ADRC) (Hasbullah et al., 2015) to ameliorate the dynamic response and prevent the problem of uncertainty parameters. Wang et al. (2018) proposed a Model Free Control based on the fractional-order sliding mode. Besides, a combination between the sliding mode control and disturbance observer was presented by Pusadkar et al. (2019). To avoid the problem of chattering, Wang et al. (2019) proposed a new integral sliding mode strategy applied to a quarter car model. In fact, the tuning of intelligent controller parameters is quite simple (Haddar et al., 2019b) while the calibration process of ADRC (Hasbullah and Faris, 2017) is more complicated since it has many tuning parameters to be chosen by the designer. Furthermore, due to the choice of the classical Extended State Observer bandwidth (Pusadkar et al., 2019; Wang et al., 2019), a trade-off between the tracking performance and the perturbation rejection can be found (Pan et al., 2015).

The presented technique in this paper takes advantage of the fast algebraic estimator (Fliess and Join, 2013) combined with an ultra-local generic model, avoiding using complex models in tracking control. In addition, the algebraic derivative method is used to provide a fast non-asymptotic state estimation in closed loop control. Also, this method is robust with respect to modelling errors and parametric uncertainties, even during critical running conditions, where such a recalibration is recommended. Moreover, a smaller number of sensors is required compared to traditional predictive controllers. The main contributions of this paper can be summarized as follows:

- Robustness: the proposed control technique performs well with respect to a large class of perturbations. The i-PID guarantees safety of the driver and satisfies the required performances.

- An improvement of computation time: obviously, the control strategy should have as small as possible computation time in order to provide fast, real-time, online estimations for processes with fast dynamics, and this estimation is not offline. This can be made possible thanks to the use of algebraic filters.

- Easy implementation and design: i-PID controller has a lower complexity problem compared to LQR. It is a simple control structure, with excellent tracking accuracy and insensitivity to unpredictable disturbance. Further, its simple structure and design methodology are also proven by the usage of a smaller number of sensors.

The organization of the paper is as follows: a half car model and its mathematical equations are presented in Section 2. Section 3 describes the Multi-Input-Multi-Output model free control technique and its principle features. The effectiveness of the proposed controller is illustrated in Section 4 with a comparative scenario between passive, PID and LQR controllers. For highlighting the superiority of ride comfort quality, Section 5 presents a discussion about the robustness of the i-PID controller. Finally, the conclusion is given in Section 6 .

\section{Half car model}

In previous works, researchers have been mostly interested in simple quarter car models with two degrees of freedom (Haddar et al., 2019b). In this work, a half car model with four degrees of 
freedom is presented. However, for improved model accuracy, this study is extended for testing an example with Multi-Input-Multi-Output (MIMO) and introducing some adaptations to the controller in order to reach a global controller with better performances and a low number of sensors. As shown in Fig. 1, the model of a half car is different than a simple quarter car model

(a)

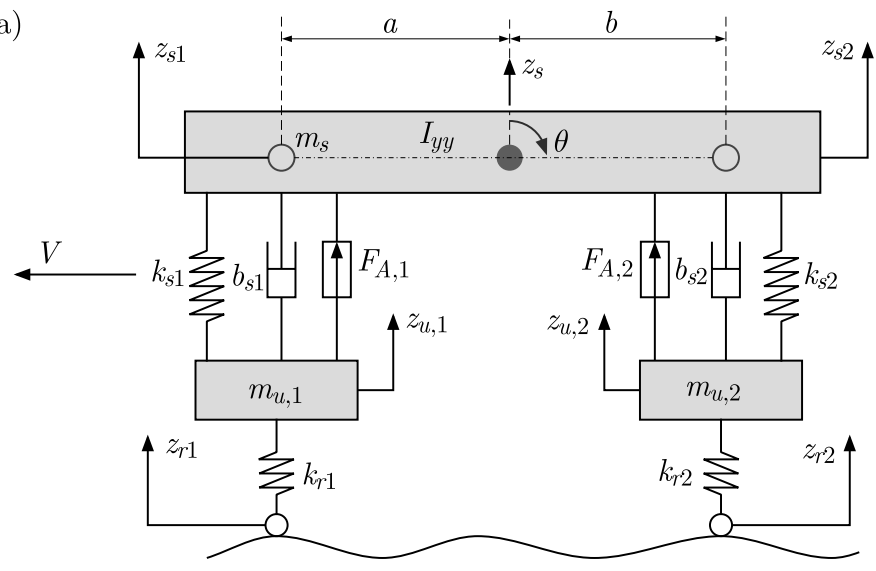

(b)

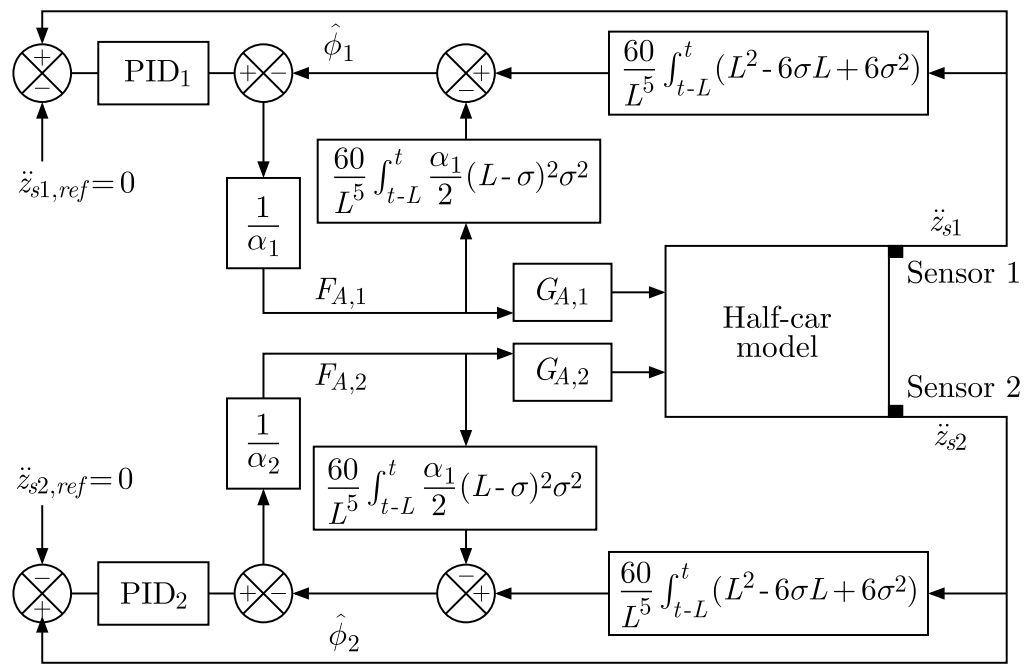

Fig. 1. (a) Suspension model with four degrees of freedom. (b) Diagram of control of MIMO model free control for the half car system

by the virtue of the presence of vehicle pitch motion. For this linear model, we assume that the pitch angle of the car body at the center of gravity CG is small enough. The equations of motion of the half car model are illustrated as

$$
\begin{aligned}
& m_{s} \ddot{z}_{s}=-k_{s 1}\left(z_{s 1}-z_{u 1}\right)-k_{s 2}\left(z_{s 2}-z_{u 2}\right)-d_{s 1}\left(\dot{z}_{s 1}-\dot{z}_{u 1}\right)-d_{s 2}\left(\dot{z}_{s 2}-\dot{z}_{u 2}\right)+F_{A, 1}+F_{A, 2} \\
& I_{y y} \ddot{\theta}=k_{s 1}\left(z_{s 1}-z_{u 1}\right) a-k_{s 2}\left(z_{s 2}-z_{u 2}\right) b+d_{s 1}\left(\dot{z}_{s 1}-\dot{z}_{u 1}\right) a \\
& \quad-d_{s 2}\left(\dot{z}_{s 2}-\dot{z}_{u 2}\right) b-F_{A, 1} a+F_{A, 2} \\
& m_{u 1} \ddot{z}_{u 1}=k_{s 1}\left(z_{s 1}-z_{u 1}\right)+d_{s 1}\left(\dot{z}_{s 1}-\dot{z}_{u 1}\right)-k_{t 1}\left(z_{u 1}-z_{r 1}\right)-F_{A, 1} \\
& m_{u 2} \ddot{z}_{u 2}=k_{s 2}\left(z_{s 2}-z_{u 2}\right)+d_{s 2}\left(\dot{z}_{s 2}-\dot{z}_{u 2}\right)-k_{t 2}\left(z_{u 2}-z_{r 2}\right)-F_{A, 2}
\end{aligned}
$$

Two relations between the body displacement and pitch motions can give expressions of displacements of sprung mass at the front and the rear tires respectively: $z_{s 1}=z_{s}-a \theta$ and $z_{s 2}=z_{s}+b \theta$.

The description of states is as follows: $z_{s}[\mathrm{~m}]$ is the displacement of the CG. $\theta[\mathrm{rad}]$ is the pitch angle. Front and rear unsprung mass displacements rate are $z_{u 1}$ and $z_{u 2}$, respectively. Front and rear sprung mass displacements are $z_{s 1}$ and $z_{s 2}[\mathrm{~m}]$. Front and rear road profiles excitations 
are $z_{r 1}$ and $z_{r 2}[\mathrm{~m}] . F_{A, 1}$ and $F_{A, 2}[\mathrm{~N}]$ are front and rear actuator force inputs. $F_{A, i}$ are inputs of the servo-hydraulic actuator to produce the required active force to the system $(i$ is the $i$-th side of the half car). According to León-Vargas et al. (2018), the dynamics of a servo-hydraulic active suspension actuator can be modelled as follows

$$
G_{A, i}(s)=\frac{1}{\frac{1}{75} s+1}
$$

In order to emphasize the feasibility of an intelligent controller in the case of a MIMO system, the objective of the paper is to adapt this kind of controller in the case of a linear half car system. Obviously, the control strategy gets more complex as the number of degrees of freedom increases. Thus, additional sensors are required. For these reasons and to avoid the use of many sensors for cost restrictions, a simplified system model is sufficient to show the effectiveness of the proposed scheme with low sensing capability. Then uncertainties and nonlinearities are added to discuss the results in terms of usefulness and effectiveness of i-PID to reject perturbations online. As aforementioned, the proposed scheme is based on the PID control method which has the advantage of being easily implementable in common industrial processes. However, PID control loses its capability when the working conditions change. On other hand, the LQR is better than PID in the sense that it gives the desired output with less control effort. Nevertheless, more sensing capability is required for controlling the four degrees of freedom model. In most cases, this necessitates a larger amount of electronic components and increases equipment cost. Similar to PID, LQR lacks the robustness property to cope with external disturbances. Based on the two controller shortcomings; i-PID can be an attractive alternative for the design of a new active controller to improve ride comfort performance of the half car model. Table 1 gives values of each parameter given in the previous equations.

Table 1. Half car parameters (León-Vargas et al., 2018)

\begin{tabular}{|c|l|c|}
\hline Variable & \multicolumn{1}{|c|}{ Definition } & Value/Unit \\
\hline \hline$m_{s}$ & Mass of car body & $580 \mathrm{~kg}$ \\
\hline$I_{y y}$ & Pitch moment of inertia & $1100 \mathrm{~kg} \mathrm{~m}{ }^{2}$ \\
\hline$m_{u 1}$ & Unsprung mass on front wheel & $40 \mathrm{~kg}$ \\
\hline$m_{u 2}$ & Unsprung mass on rear wheel & $40 \mathrm{~kg}$ \\
\hline$k_{s, 1}$ & Front suspension stiffness coefficient & $23500 \mathrm{~N} / \mathrm{m}$ \\
\hline$k_{s, 2}$ & Rear suspension stiffness coefficient & $23500 \mathrm{~N} / \mathrm{m}$ \\
\hline$d_{s 1}$ & Front tire damping coefficient & $1500 \mathrm{Ns} / \mathrm{m}$ \\
\hline$d_{s 2}$ & Rear tire spring coefficient & $1600 \mathrm{Ns} / \mathrm{m}$ \\
\hline$k_{t 1}$ & Front spring coefficient & $190000 \mathrm{~N} / \mathrm{m}$ \\
\hline$k_{t 2}$ & Rear tire spring coefficient & $190000 \mathrm{~N} / \mathrm{m}$ \\
\hline$a$ & Distance of front axle to COM & $1.0 \mathrm{~m}$ \\
\hline$b$ & Distance of rear axle to COM & $1.5 \mathrm{~m}$ \\
\hline
\end{tabular}

\section{Model free control technique}

An intelligent controller is able to update online its scaling parameters under different conditions (Fliess and Join, 2013). The key element of an intelligent controller is elimination of the use of a sophisticated model and rejection of un-modeled perturbations online. The design of an i-PID controller based on algebraic tools was detailed in Haddar et al. (2019a). In fact, the proposed finite estimation for disturbance rejection, which is algebraically designed, can avoid the use of statistical and asymptotic estimation techniques. Furthermore, the implementation is 
fast compared to methods that use statistical techniques like using the Kalman filter for LQR controller. The most important advantage is that the identification can be made online and, in particular, in a closed loop in the presence of noise. The mathematical model of the controlled half car can be replaced by two ultra-local model equations with a reduced number of scaling parameters. Fliess and Join (2013) illustrated the expression of ultra-local-model as follows

$$
y_{i}^{(n)}=\phi_{i}+\alpha_{i} F_{A, i}
$$

where $y_{i}$ is the measured signal, $F_{A, i}$ is the power delivered by the actuator, $i$ is the $i$-th side of the half car, $n$ is equal to 2 . For getting $\phi_{i}$ and $\alpha_{i} F_{A, i}$ with the same magnitude, the operator should be fixed constant $\alpha_{i} \in \mathbb{R}$. Internal and external phenomena that should be compensated are regrouped in the term $\phi_{i}$.

The feedback loop of classical PID control is modified and will incorporate a cancellation term that represents the output of the algebraic estimator. The i-PID controller is given by

$$
F_{A, i}=\underbrace{-\frac{\widehat{\phi}_{i}}{\alpha_{i}}}_{\text {Cancellation term }}+\underbrace{\frac{\ddot{y}_{r e f, i}-\left(K_{P, i} e+K_{I, i} \int e+K_{D, i} \dot{e}\right)}{\alpha_{i}}}_{\text {Closed loop tracking }}
$$

where: $e=y_{i}-y_{r e f, i}$ is the tracking error, $y_{r e f, i}$ is the reference trajectory and is set to zero in this work (Wang et al., 2018), $y_{i}$ is the measured acceleration on the left corner of the upper mass for $i=1$ and represents the measured acceleration on the right corner of the upper mass for $i=2$, $K_{P, i}, K_{I, i}$ and $K_{D, i}$ are the proportional gain, integral gain and derivative gain respectively, $i$ is the $i$-th side of the half car.

The differential algebra rules required to design the finite time estimator of $\widehat{\phi}_{i}$ are summarized in the following steps (Haddar et al., 2019a):

Step 1 - Laplace transformation of Eq. (3.1),

Step 2 - twice differentiation process of the previous equation with respect to the complex terms $s$ for cancelling out initial conditions,

Step 3 - avoiding the positive power introduced by the highest degree of $s$ and multiplying both sides by $s^{-3}$,

Step 4 - passing from the Laplace domain to time domain and following the operational calculus rules (Fliess and Join,2013).

Those steps yield an algebraic estimator with low complexity to be implemented in real time and which is characterized by

$$
\widehat{\phi}_{i}=\frac{60}{L^{5}} \int_{t-L}^{t}\left(L^{2}-6 \sigma L+6 \sigma^{2}\right) y_{i}(\sigma)-\frac{\alpha_{i}}{2}(L-\sigma)^{2} \sigma^{2} F_{A, i}(\sigma) d \sigma
$$

The window of integration $[t, t-L]$ should be designed by small width $L$ for goodness of identification and reduced time computation.

The advantage of estimators given above can be represented in two important points: 1) unlike classical observer, there is no need for any information about initial conditions and this decreases the complexity of implementation, 2) the implementation in real case is not expensive and can be achieved with digital filters. In fact, the integrals in Eq. (3.3) function as low pass filters, which generally reduces the impact of noise and exogenous disturbances of a noise-corrupted signal.

A block diagram of the model-free control implemented in the case of the half car is summarized in Fig. 1b. The scheme shows that neglected parts can be compensated without knowledge of the model by using the above information of the control signal $F_{A, i}$ (front and rear actuator force inputs) and the output signals $\ddot{z}_{s, i}$. The two accelerometers are implemented on the left and right corner of the sprung mass. 


\section{Simulation results}

In order to show the effectiveness of the proposed controller in the dynamic behaviour of the half car system, a comparison with PID and LQR in both time and frequency domains has been investigated.

In terms of conceptual design, the i-PID and PID controllers are simpler than LQR. However, PID and LQR design require exact information about the vehicle model and its dynamics. Frequently, an empirical process is adopted to select the optimal control gains. Meanwhile, the i-PID controller is able to adequately tune its scaling parameters online under different driving conditions.

The controller concept was created to minimize the cost functional index

$$
J=\int_{0}^{\infty}\left[\mathbf{x}^{\mathrm{T}}(t) \mathbf{Q} \mathbf{x}(t)+2 \mathbf{x}^{\mathrm{T}}(t) \mathbf{N F}_{A_{L Q R}}(t)+\mathbf{F}_{A_{L Q R}}^{\mathrm{T}}(t) \mathbf{R F}_{A_{L Q R}}(t)\right] d t
$$

where $\mathbf{F}_{A_{L Q R}}=-\mathbf{K}_{l q r} \mathbf{x}$ is the actuator force produced by LQR controller. $\mathbf{x}$ is an $8 \times 1$ state vector: $\mathbf{x}=\left[\ddot{z}_{s}, \ddot{\theta}, z_{s 1}-z_{u 1}, z_{s 2}-z_{u 2}, \dot{z}_{s 1}, \dot{z}_{s 2}, z_{u 1}-z_{r 1}, z_{u 2}-z_{r 2}\right]^{\mathrm{T}}$. As indicated before, the implementation process is more complicated in the case of LQR. LQR has a drawback that it assumes that all the states given by $\mathbf{x}$ are measurable. An observer for different states should be designed such as the Kalman Filter (see Haddar et al., 2019a). Q, R and $\mathbf{N}$ are the regulator settings depending on the weighting parameters $\rho_{k}, k=0, \ldots, 11$

$$
\begin{aligned}
J= & \int_{0}^{\infty}\left[\rho_{0} \ddot{z}_{s}^{2}+\rho_{1} \ddot{\theta}^{2}+\rho_{2}\left(z_{s 1}-z_{u 1}\right)^{2}+\rho_{3}\left(z_{s 2}-z_{u 2}\right)^{2}+\rho_{4} \dot{z}_{s 1}^{2}+\rho_{5} \dot{z}_{s 2}^{2}\right. \\
& \left.+\rho_{6}\left(z_{u 1}-z_{r 1}\right)^{2}+\rho_{7}\left(z_{u 2}-z_{r 2}\right)^{2}+\rho_{8} \dot{z}_{u 1}^{2}+\rho_{9} \dot{z}_{u 2}^{2}+\rho_{10} F_{A 1}^{2}+\rho_{11} F_{A 2}^{2}\right] d t
\end{aligned}
$$

$\mathbf{Q}, \mathbf{R}$ and $\mathbf{N}$ are weighted to get a good ride quality without significant sacrifice in suspension deflection and tire deflection (Wakeham and Rideout, 2011; Rajamani, 2011)

$$
\mathbf{K}_{l q r}=10^{4}\left[\begin{array}{cccccccc}
-0.2596 & 0.0739 & 1.4495 & 0.0373 & 0.9439 & 0.0418 & -0.4197 & -0.0164 \\
-0.7628 & 0.0053 & -2.8081 & -0.2541 & -0.4362 & -0.0141 & 1.5129 & 0.0641
\end{array}\right]
$$

Ride comfort is the key element to be investigated. For this reason, a bumpy road profile is chosen to be the first excitation type to investigate the dynamic response of the vehicle. To identify the transient-response features of the proposed model free control, the bumpy road curve is used. The mathematical equation of the road bump is

$$
z_{r}(t)= \begin{cases}H_{0}\left[1-\cos \left(\omega_{r} t\right)\right] & \frac{2 \pi}{\omega_{r}} \leqslant t \leqslant \frac{4 \pi}{\omega_{r}} \\ 0 & \text { otherwise }\end{cases}
$$

where: $\omega_{r}=2 \pi V_{h} / D, V_{h}=12 \mathrm{~m} / \mathrm{s}$ is the vehicle speed, $H_{0}=0.08 \mathrm{~m}$ is height of the bump, $D=9.1 \mathrm{~m}$ is longitudinal distance.

\subsection{Time domain responses}

Time responses of the vehicle dynamics are illustrated in Figs. 2-6. These figures provide comparisons between uncontrolled and controlled models. 
(a)

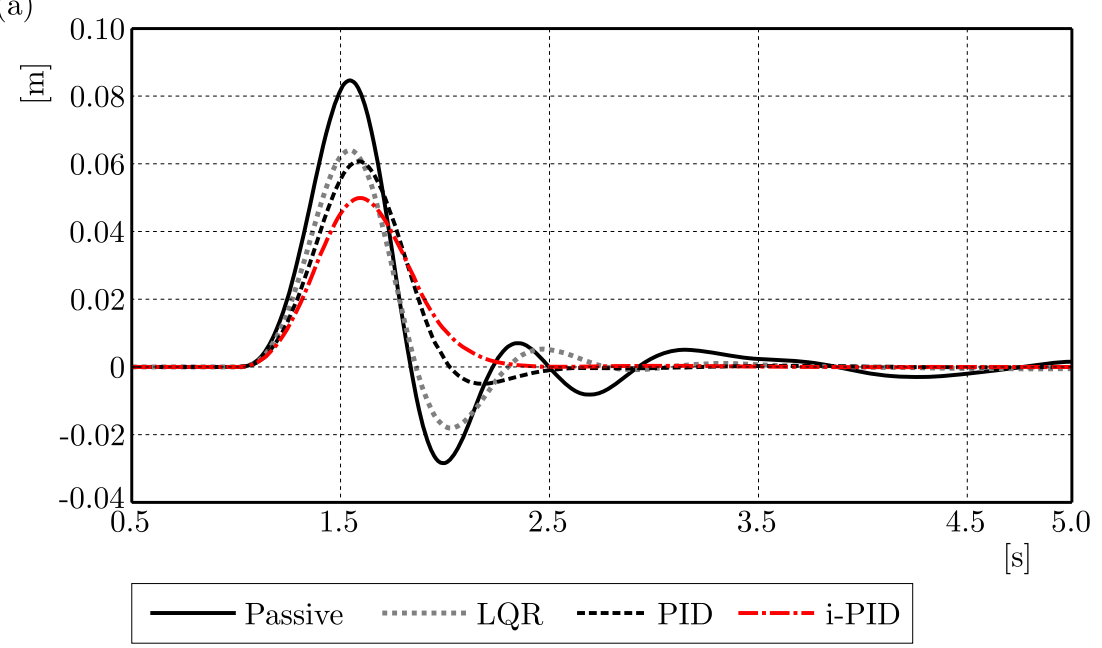

(b)

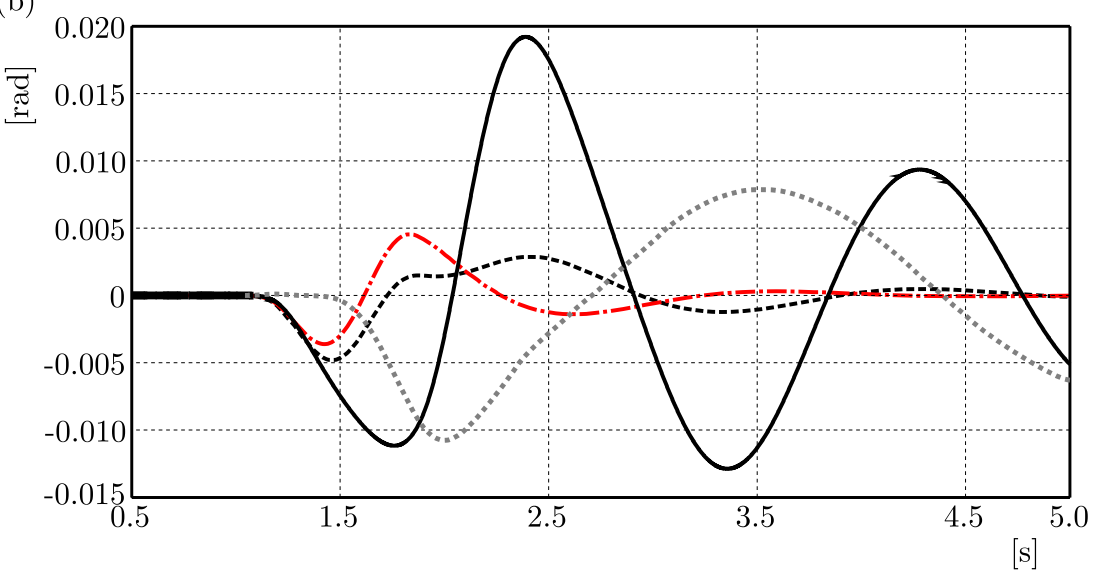

Fig. 2. Displacement responses of: (a) vehicle body, (b) pitch motion

- Minimizing the bump effect - the smaller maximum peaks in the presence of the bump and the lowest settling time are achieved by i-PID as shown in Fig. 2. In fact, the estimated signals included in $\widehat{\phi}_{i}$, are able to enhance the system transient response and to cancel the impact of offset.

- Ride comfort - passive system shows the worst vibration attenuation compared to systems equipped by active controllers. In Table 2, the i-PID strategy allows one to produce the lowest level of vertical and pitch acceleration amplitude than LQR controller and PID (the highest level of attenuation percentage is obtained by i-PID by $66 \%$ for vertical acceleration and $59 \%$ for angular acceleration). Furthermore, the i-PID controller has fastest transient response as depicted in Figs. 3 and 4 . The estimated signals included in different terms $\widehat{\phi}_{i}$ act as an additive damping force for providing better oscillatory comfort.

- Suspension deflection - Figure 5 shows active half car models deflection compared with the uncontrolled case. The RMS values given by Table 2 indicate that i-PID is able to prevent the system from beating its travel limits more than PID and LQR. It is known that the improving of ride comfort with LQR presents a trade-off with suspensions deflection criteria. The controlled half car model must not exceed the limit given as $\pm 0.1 \mathrm{~m}$.

- Road holding - the contact between the wheel and the road should be maximized. As given by Fig. 6 and Table 2, i-PID technique can be thought of as a compromising control strategy among other classical control techniques. In order to ensure driving safety and road holding stability, the dynamic load of the tire should be smaller than its static load. 
Table 2. The RMS values of different motions

\begin{tabular}{|l|c|c|c|c|}
\hline \multicolumn{1}{|c|}{$\chi_{R M S}=\frac{\|\chi\|}{n} \sqrt{\frac{1}{n} \sum_{i=1}^{n} \chi_{i}^{2}}$} & Passive & PID & LQR & i-PID \\
\hline \hline Body acceleration $\ddot{z}_{s}$ & 0.7883 & $0.3686(\uparrow 53 \%)$ & $0.5101(\uparrow 35 \%)$ & $0.2606(\uparrow 66 \%)$ \\
\hline Angular acceleration $\ddot{\theta}$ & 0.1291 & $0.0605(\uparrow 53 \%)$ & $0.0762(\uparrow 40 \%)$ & $0.0521(\uparrow 59 \%)$ \\
\hline Front acceleration $\ddot{z}_{s 1}$ & 0.7596 & $0.3923(\uparrow 48 \%)$ & $0.5059(\uparrow 33 \%)$ & $0.2860(\uparrow 62 \%)$ \\
\hline Rear acceleration $\ddot{z}_{s 2}$ & 0.8663 & $0.3451(\uparrow 60 \%)$ & $0.5369(\uparrow 38 \%)$ & $0.2467(\uparrow 71 \%)$ \\
\hline Body displacement & 0.0214 & $0.0161(\uparrow 24 \%)$ & $0.0173(\uparrow 19 \%)$ & $0.0138(\uparrow 35 \%)$ \\
\hline Angular displacement $\theta$ & 0.0080 & $0.0018(\uparrow 77.5 \%)$ & $0.0066(\uparrow 16 \%)$ & $0.0015(\uparrow 81 \%)$ \\
\hline $\begin{array}{l}\text { Front suspension deflection } \\
z_{s 1}-z_{u 1}\end{array}$ & 0.0180 & $0.0148(\uparrow 18 \%)$ & $0.0161(\uparrow 10.5 \%)$ & $0.0142(\uparrow 22 \%)$ \\
\hline $\begin{array}{l}\text { Rear suspension deflection } \\
z_{s 2}-z_{u 2}\end{array}$ & 0.0112 & $0.0081(\uparrow 28 \%)$ & $0.0099(\uparrow 12 \%)$ & $0.0059(\uparrow 47 \%)$ \\
\hline Front tire deflection & 0.0024 & $0.0015(\uparrow 37.5 \%)$ & $0.0017(\uparrow 30 \%)$ & $0.0013(\uparrow 46 \%)$ \\
\hline Rear tire deflection $z_{u 2}-z_{r 2}$ & 0.0015 & $0.0006(\uparrow 60 \%)$ & $0.0009(\uparrow 40 \%)$ & $0.0005(\uparrow 66 \%)$ \\
\hline
\end{tabular}

(a)
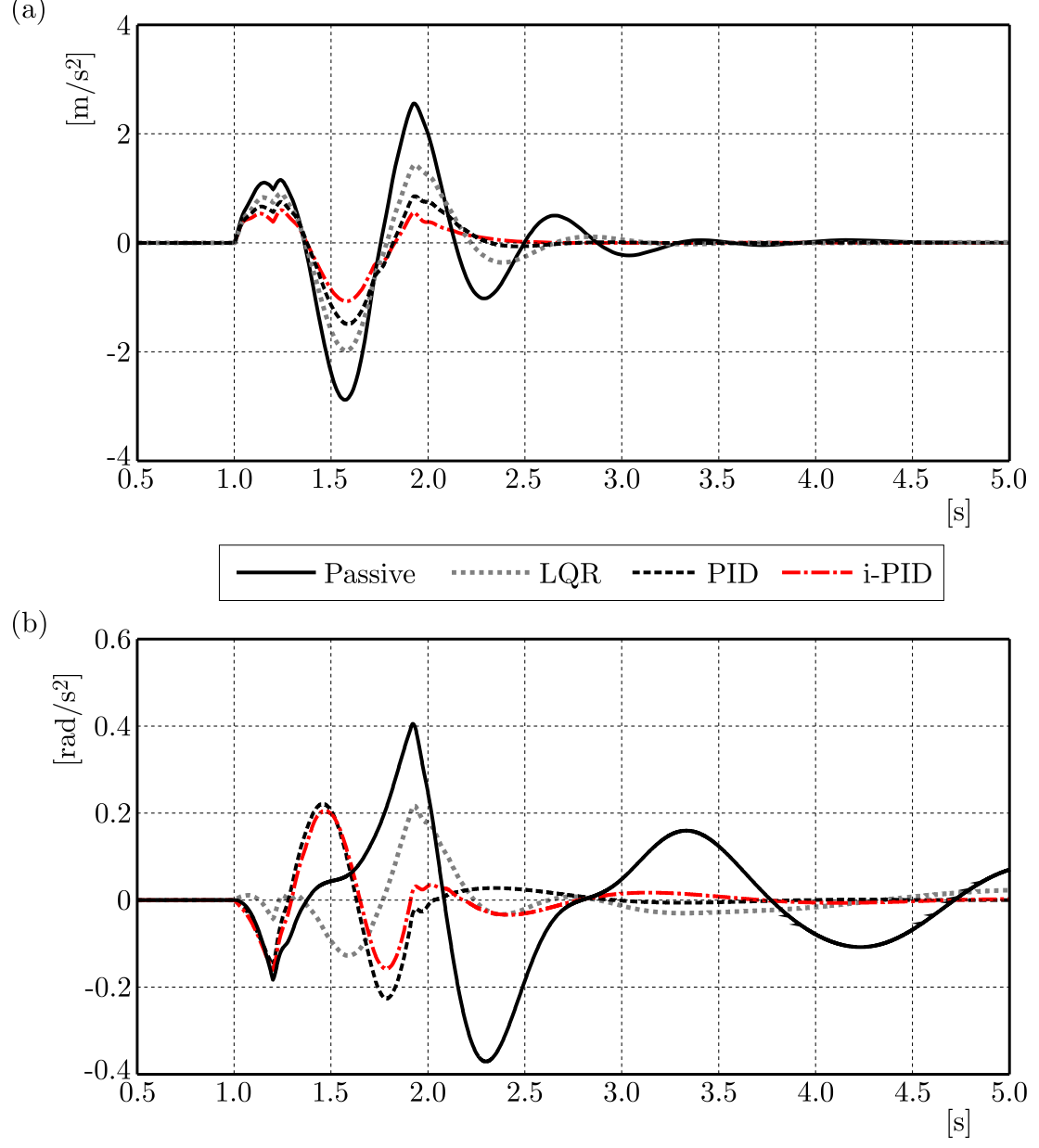

Fig. 3. Acceleration responses of: (a) vehicle body, (b) pitch motion 
(a)

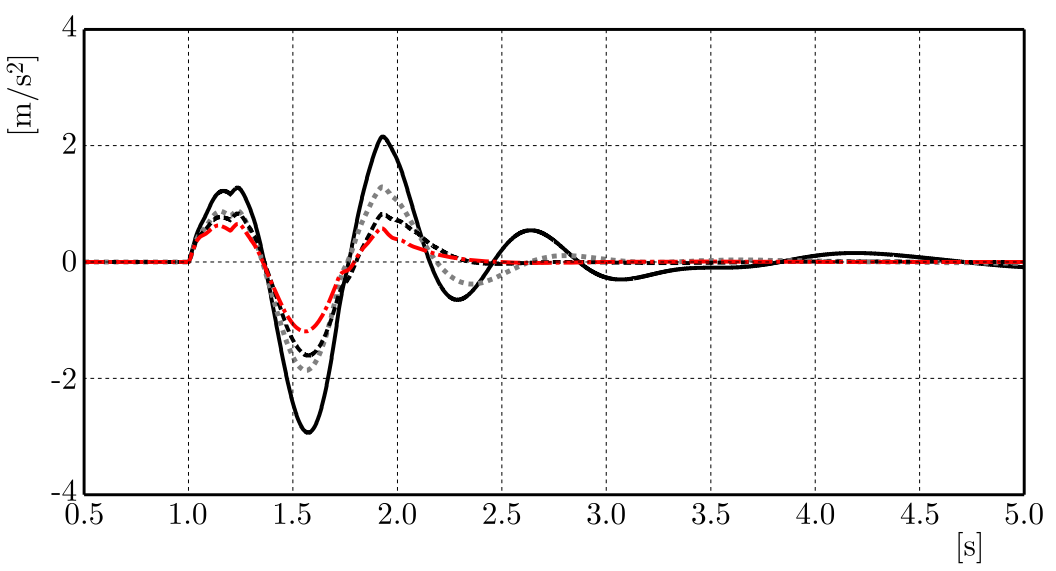

(b)

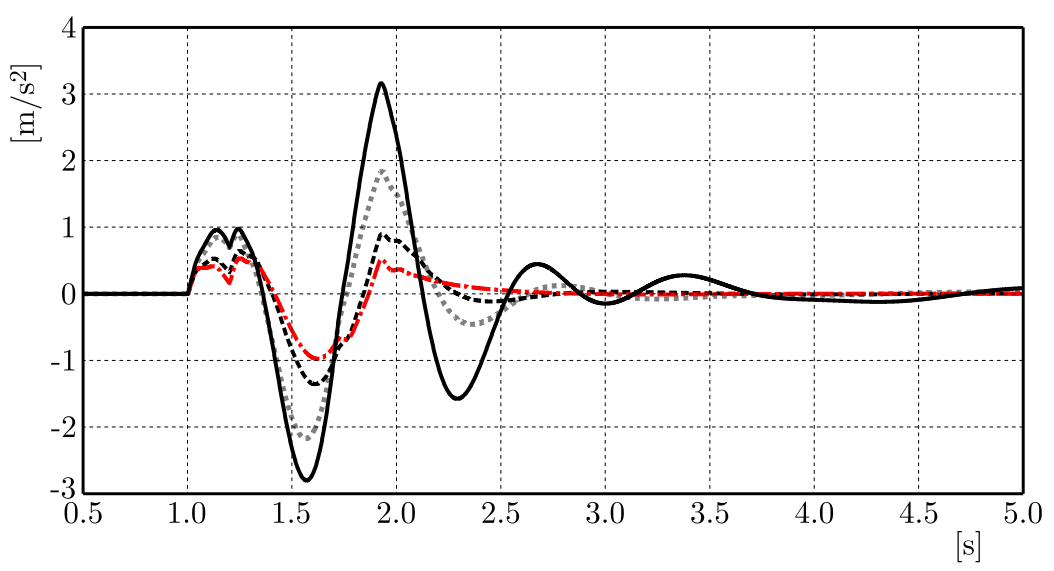

Fig. 4. Acceleration responses on: (a) front, (b) rear corner of the upper mass

The magnitude of normalized tire deflection for each side should be lower than unity

$$
N T D_{1}=\frac{k_{t 1}\left(z_{u 1}-z_{r 1}\right)}{9.81\left(\frac{b m_{s}}{a+b}+m_{u 1}\right)}<1 \quad N T D_{2}=\frac{k_{t 2}\left(z_{u 2}-z_{r 1}\right)}{9.81\left(\frac{a m_{s}}{a+b}+m_{u 2}\right)}<1
$$

Different presented active suspension algorithms show good road holding since the dynamic tire load did not exceed the static tire load in any case. Moreover, the RMS amelioration with the i-PID algorithm is higher than that exhibited by the PID and LQR controllers. i-PID is able to cope with the conflicting demands between ride comfort and road holding.

- Actuator force - the cancellation term, in the feedback loop, could compensate the disturbance produced by the road profile. In fact, it allows one to bring the dynamic response back to steady state faster and enhances attenuation of oscillations. The i-PID controller performed better in terms of ride comfort, good road holding and best rattle space. However, with i-PID, some penalty is given to the actuator force compared to LQR controller (Fig. 7).

\subsection{Frequency domain responses}

To further investigate the performance of the integrated intelligent controller, frequency plots of different transfer functions with respect to front and rear excitations, respectively, in the frequency band $[0-20] \mathrm{Hz}]$ are presented in Figs. 8 and 9. 
(a)
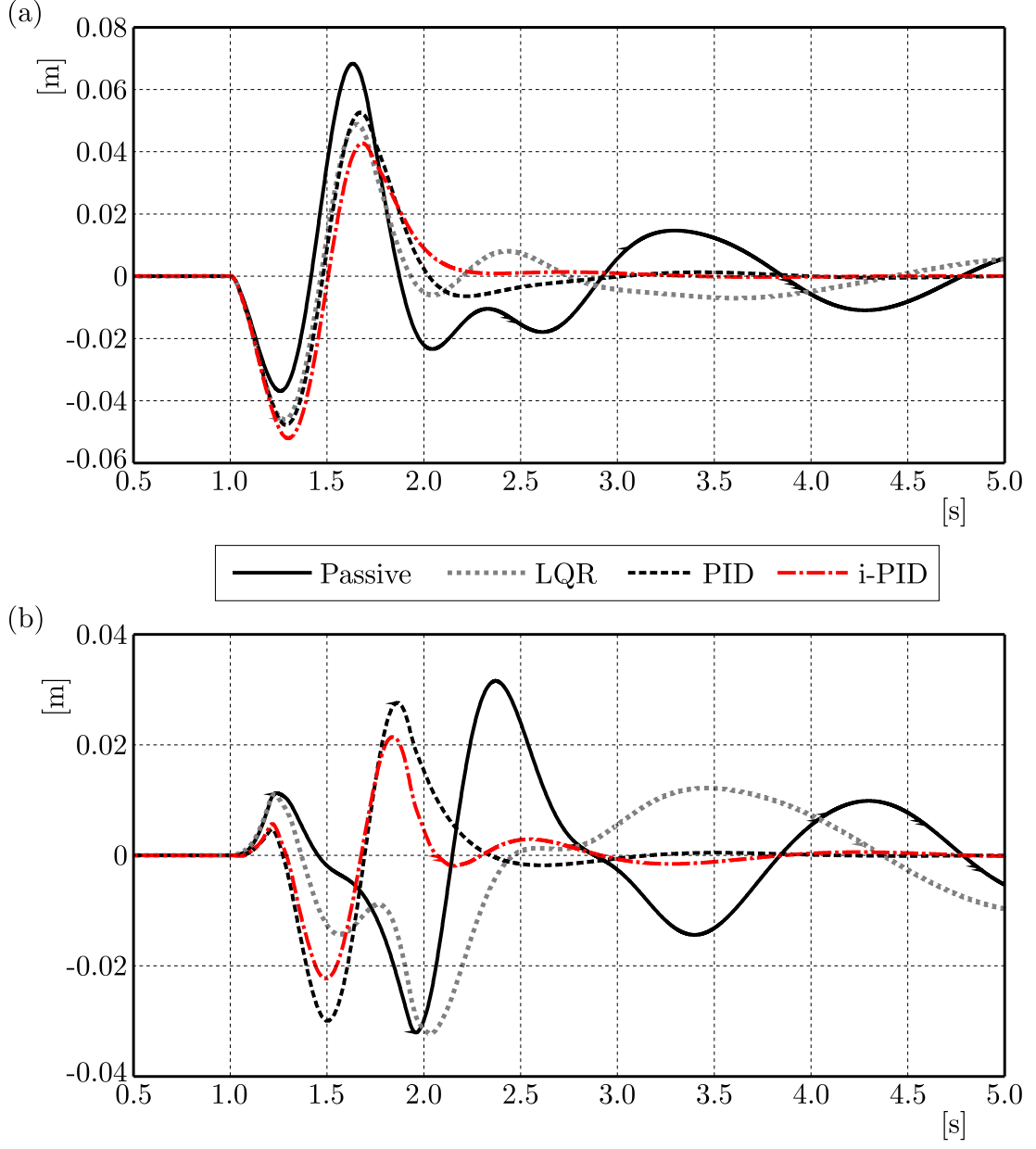

Fig. 5. Time-domain response of (a) front and (b) rear suspension deflection

Generally, it can be concluded that i-PID control improves the response at the sprung mass natural frequency more than other controllers. On the one hand, to achieve good ride comfort, a minimization of the vertical acceleration should be attempted in the frequency range from $4 \mathrm{~Hz}$ to $8 \mathrm{~Hz}$ (according to ISO 2631(1997)). The different plots of the frequency responses show that the proposed controller yields a lower value of gain over the mentioned frequency band. Thus, the proposed controller improves ride comfort.

In the case of LQR, the advantage of increasing the ride comfort was coupled with a little increase in the response at the wheel mass natural frequency. The transfer functions of suspension deflections are enhanced at unsprung and sprung mass peak resonances. Nonetheless, the performances are worse at low frequencies. The tire deflection transmissibility is enhanced at both resonant frequencies. In fact, this result given by LQR depends on the choice of the weighting factors in matrices $\mathbf{Q}$ and $\mathbf{R}$ (Faris et al., 2009). There is a trade-off between performances. In fact, different cases according to Rajamani (2011) are adopted (empirical tuning of weighting matrices). As a result, the tuning of LQR is not straightforward as the i-PID controller.

The intelligent part in PID control improves the response at the peak resonance of the sprung mass natural frequency while slightly increasing the response at the unsprung mass natural frequency. As already seen from the time responses, the i-PID controller is more efficient than other techniques and provides a good compromise between required performances. 
(a)

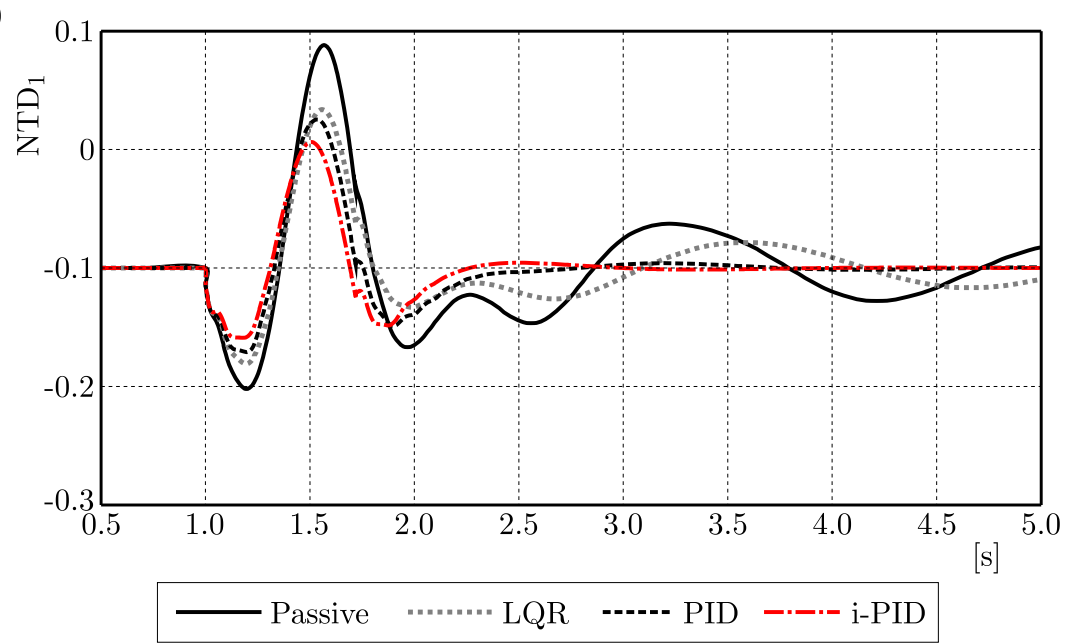

(b)

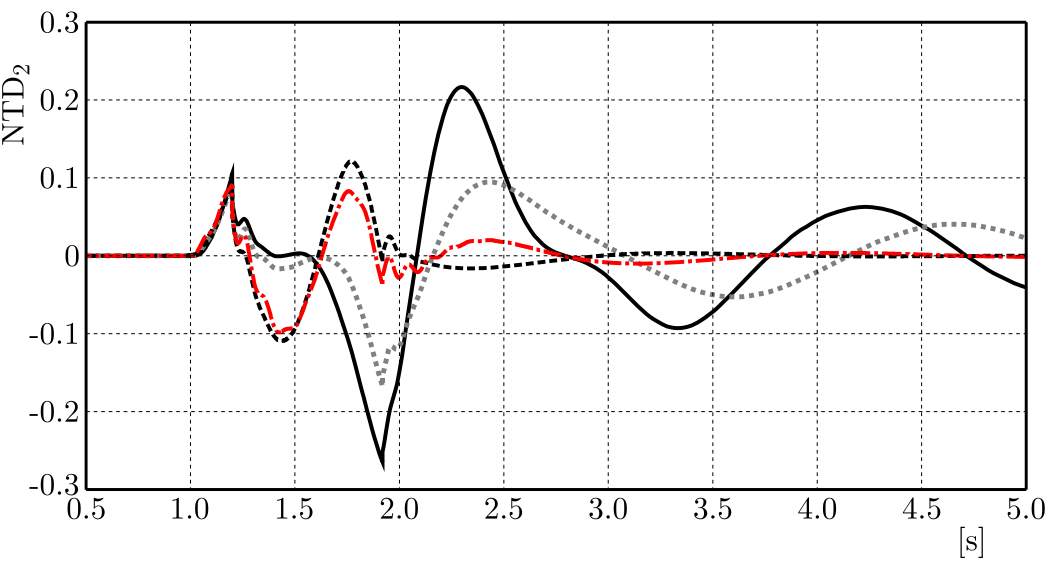

Fig. 6. Time-domain response of (a) front and (b) rear tire deflection

\section{Parametric sensitivity}

In most applications, the design of active suspension control is heavily oriented to ride comfort criteria. As a final case study, a verification of the robustness of the proposed strategy in analyzing parametric sensitivity under variable load and speed of the vehicle is carried out.

\subsection{Variation of vehicle load}

In reality, vehicle mass is variable and should be considered as an uncertain parameter. Regarding robustness, the model free control design is able to handle the sprung mass uncertainty and maintain the same level of required performance. In the simulation study presented below, RMS is assumed to vary in the interval with an increment of $10 \%$. Figure 10 and Table 3 show the sprung mass acceleration with variation of body mass in the case of different controllers.

In the case of PID, the peak to peak levels of body acceleration is decreased with augmenting body mass quantities. The settling time is more sensitive to variation of the mass in the case of passive and LQR controller. Clearly, under variable load, LQR requires a new calibration, and the weighting factors should be changed in matrices $\mathbf{Q}$ and $\mathbf{R}$. In fact, a precise mathematical model of the half car system is required to recalculate the gain $\mathbf{K}$. In general, it can be seen that i-PID is able to reject online the perturbation caused by the increasing payload. Moreover, the feedback process included in i-PID is independent of the half car model parameters. 


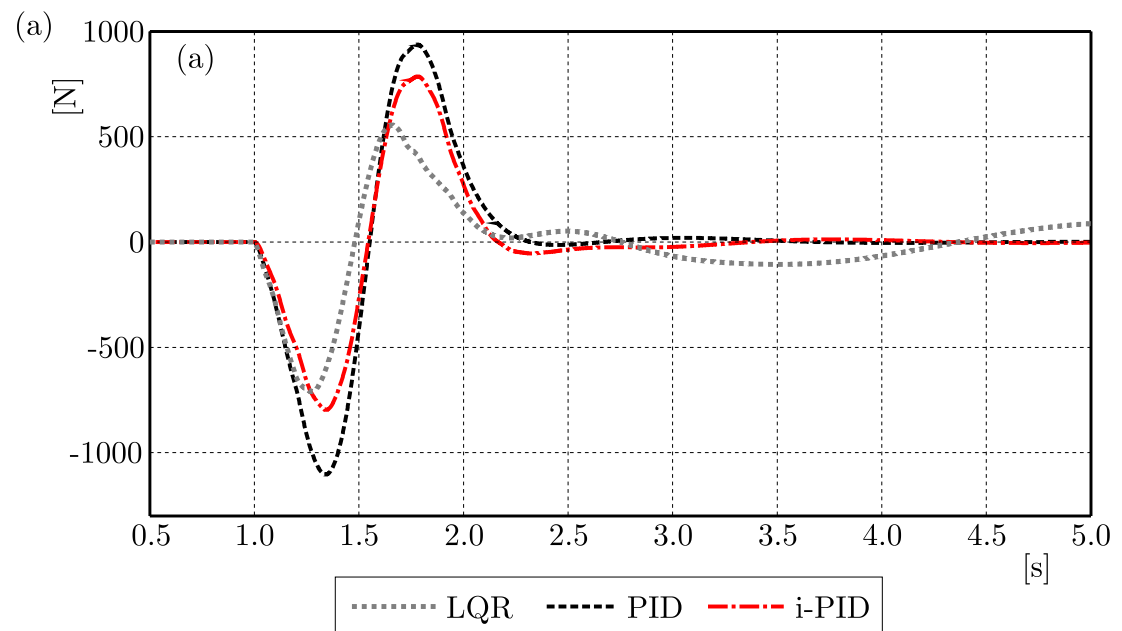

(b)

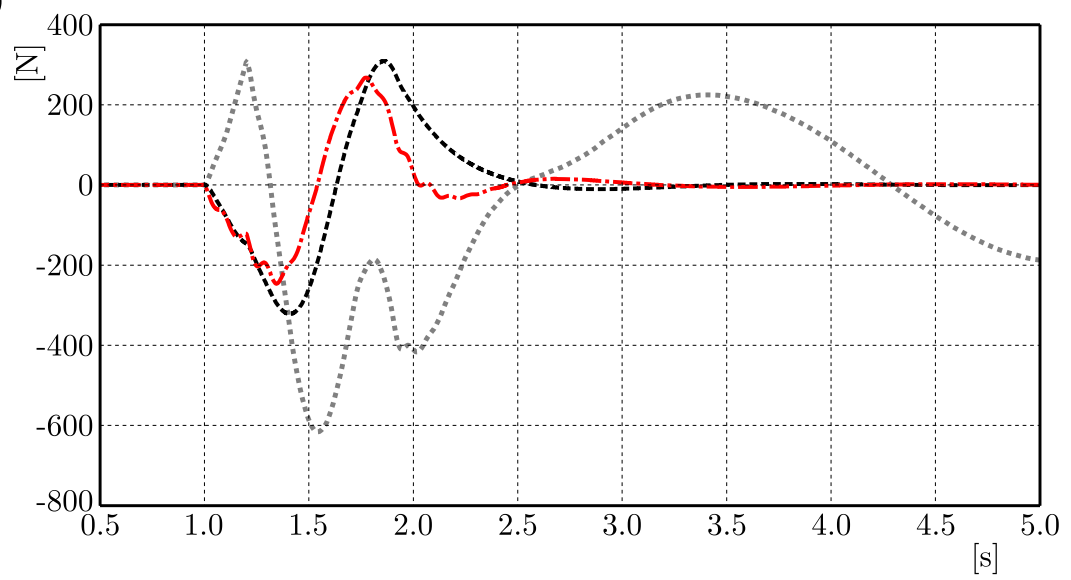

Fig. 7. Required power energy: (a) front and (b) rear control input

\subsection{Variation of vehicle speed}

In order to investigate the influence of vehicle speed variation on ride comfort quality, the half car system is driven on a random road profile ISO class A with an initial velocity speed equal to $15 \mathrm{~m} / \mathrm{s}$. Therefore, at $t=10 \mathrm{~s}$, with the same speed, the vehicle is driven under road class B. At $t=20 \mathrm{~m} / \mathrm{s}$ the speed increases from $15 \mathrm{~m} / \mathrm{s}$ to $20 \mathrm{~m} / \mathrm{s}$, and there is a permutation between road roughness from road class B to road class $\mathrm{C}$. The equation of a random road profile is presented as follows

$$
\dot{z}_{r i}(t)=-2 \pi V_{\text {speed }} n_{0} z_{r i}(t)+2 \pi \sqrt{G_{0} V_{\text {speed }}} w(t)
$$

where $z_{r i}(t)$ is the front and rear random road displacement, $V_{\text {speed }}$ is the vehicle velocity, $w(t)$ represents the random signal with a zero mean unity variance, $n_{0}=0.1$ is the spatial frequency, equal to $0.1 \mathrm{cycle} / \mathrm{m}, G_{0}$ is the road roughness coefficient which depends on the road class (ISO8608, 1995). In this paper: $G_{0}\left(\operatorname{Road} \mathrm{A}=16 \cdot 10^{-6} \mathrm{~m}^{2} /\right.$ cycles $\left./ \mathrm{m}\right), G_{0}(\operatorname{Road} \mathrm{B}=$ $64 \cdot 10^{-6} \mathrm{~m}^{2} /$ cycles $\left./ \mathrm{m}\right)$ and $G_{0}\left(\right.$ Road $\mathrm{C}=256 \cdot 10^{-6} \mathrm{~m}^{2} /$ cycles $\left./ \mathrm{m}\right)$.

According to Fig. 11 and Table 4, it can be seen that the vehicle speed has much impact on the ride comfort. When changing from road class A to class B (with a speed of $15 \mathrm{~m} / \mathrm{s}$ ), the RMS increases by $50 \%$ and when moving from road of class B to class C (with a speed of $20 \mathrm{~m} / \mathrm{s}$ ), the RMS increases by $30 \%$ for classical controllers, with the exception of i-PID which shows less sensitivity. In fact, when changing the speed from $15 \mathrm{~m} / \mathrm{s}$ to $20 \mathrm{~m} / \mathrm{s}$, the PID and LQR failed to reduce high oscillation caused by the speed increase. Pure derivative included in the PID 

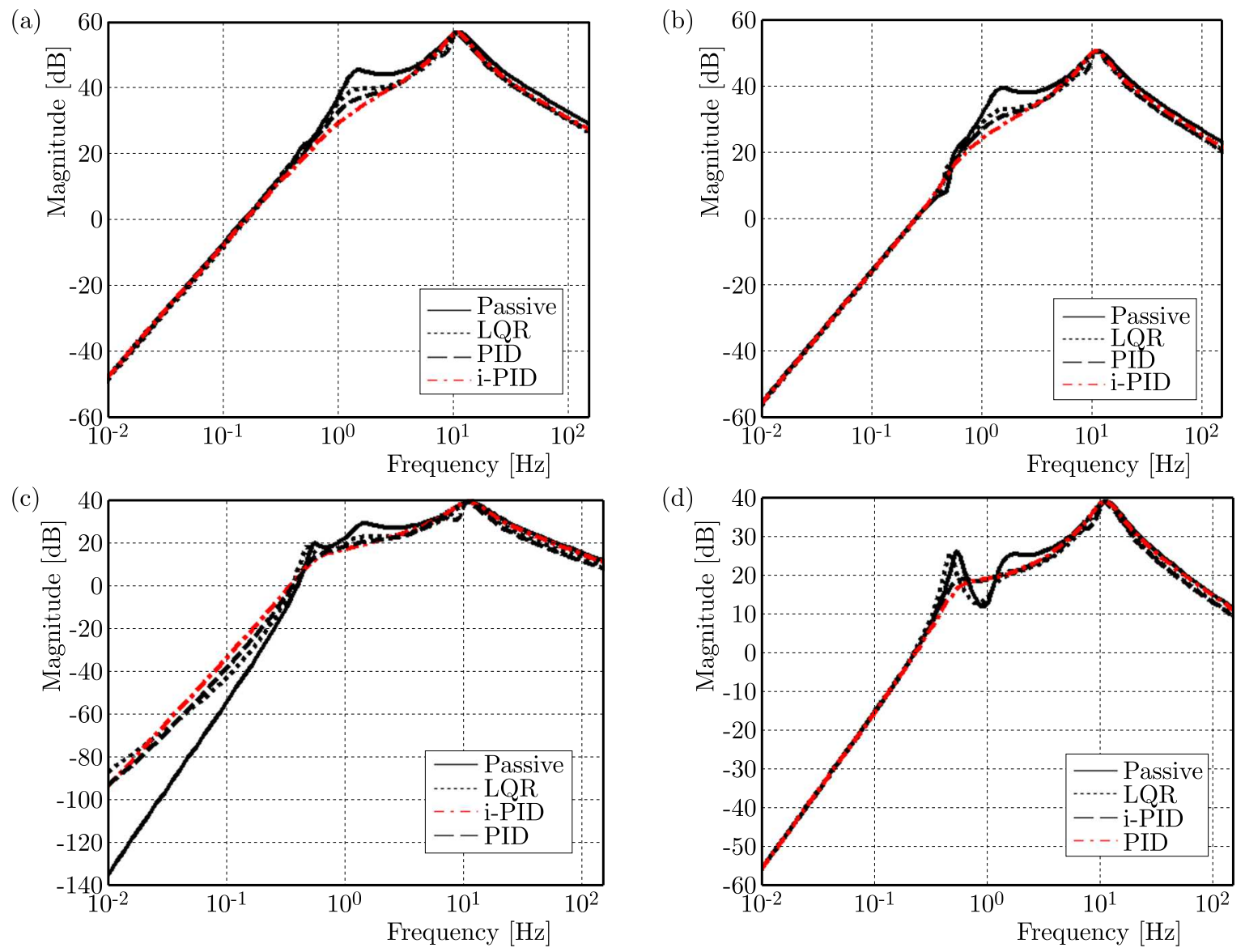

Fig. 8. Transfer functions of: (a) body acceleration with respect to front excitation, (b) body acceleration with respect to rear excitation, (c) angular acceleration with respect to front excitation, (d) angular acceleration with respect to rear excitation

(a)

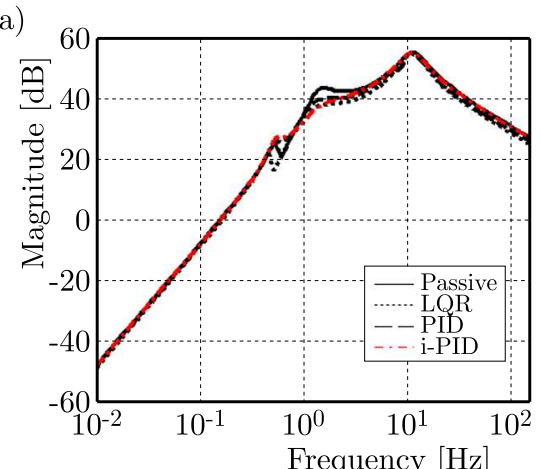

(d)

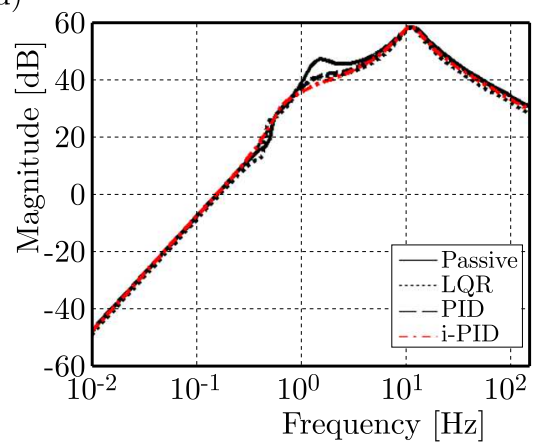

(b)

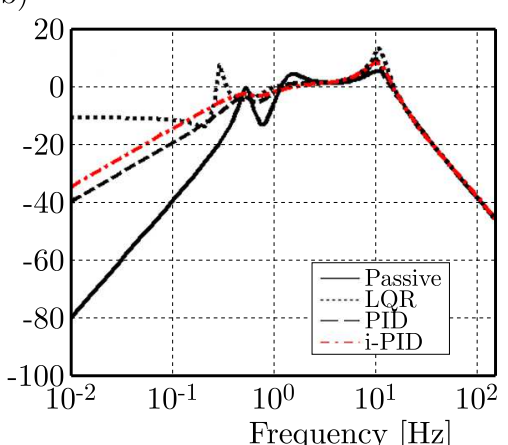

(e)

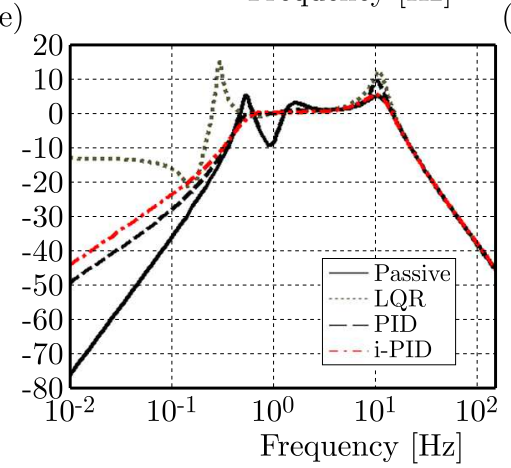

(c)

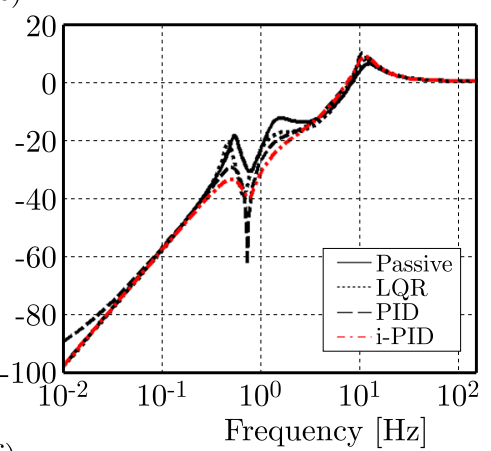

(f)

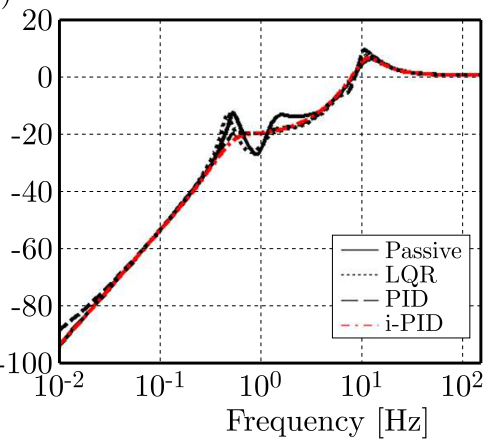

Fig. 9. Transfer functions of: (a) front acceleration with respect to front excitation, (b) front suspension deflection with respect to front excitation, (c) front tire deflection with respect to front excitation,

(d) rear acceleration with respect to rear excitation, (e) rear suspension deflection with respect to rear excitation, (f) rear tire deflection with respect to rear excitation 


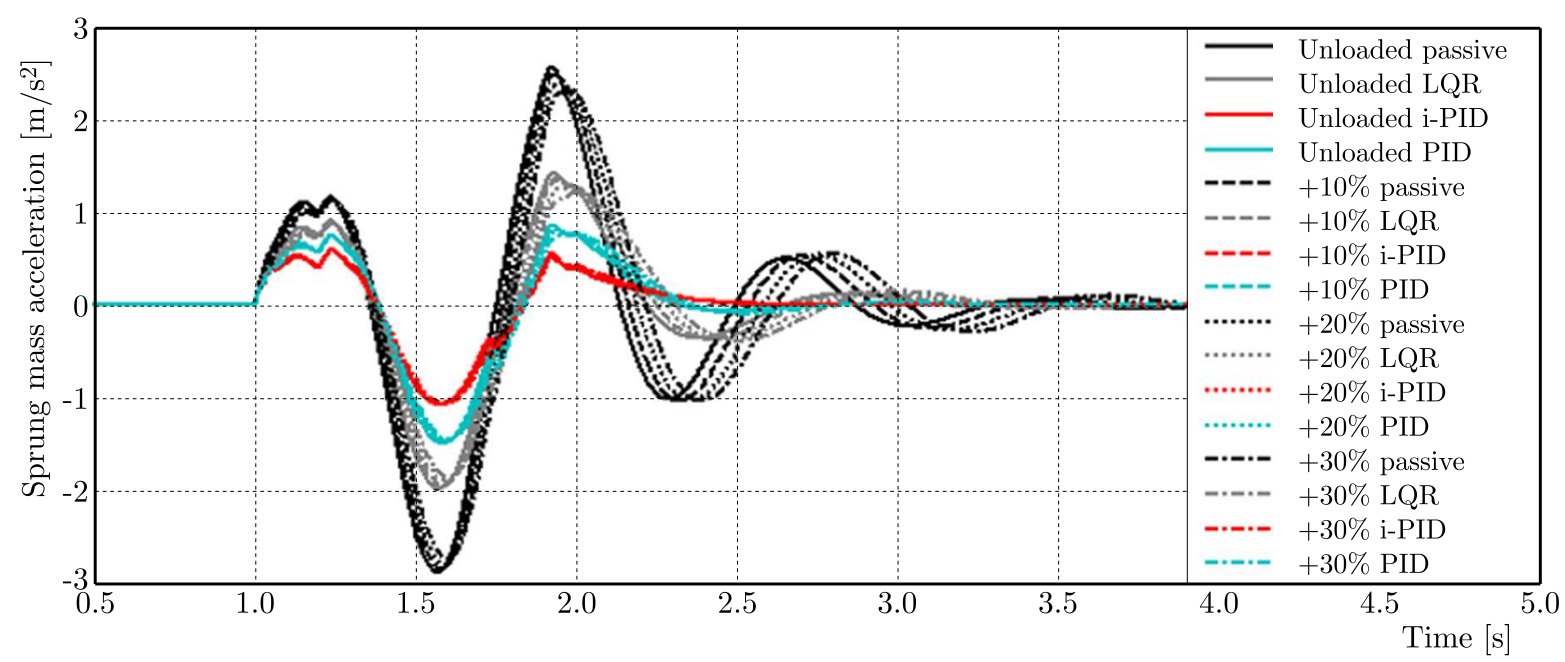

Fig. 10. Effect of body mass variation on ride comfort

Table 3. The RMS with mass variation

\begin{tabular}{|l|l|l|l|l|}
\hline$\chi_{R M S}=\frac{\|\chi\|}{n} \sqrt{\frac{1}{n} \sum_{i=1}^{n} \chi_{i}^{2}}$ & Passive & PID & LQR & i-PID \\
\hline \hline Unloaded & 0.7883 & 0.3686 & 0.5163 & 0.2606 \\
\hline$+10 \%$ & 0.7907 & 0.3687 & 0.5146 & 0.2607 \\
\hline$+20 \%$ & 0.7984 & 0.3682 & 0.5008 & 0.2619 \\
\hline$+30 \%$ & 0.7922 & 0.3700 & 0.5001 & 0.2620 \\
\hline
\end{tabular}

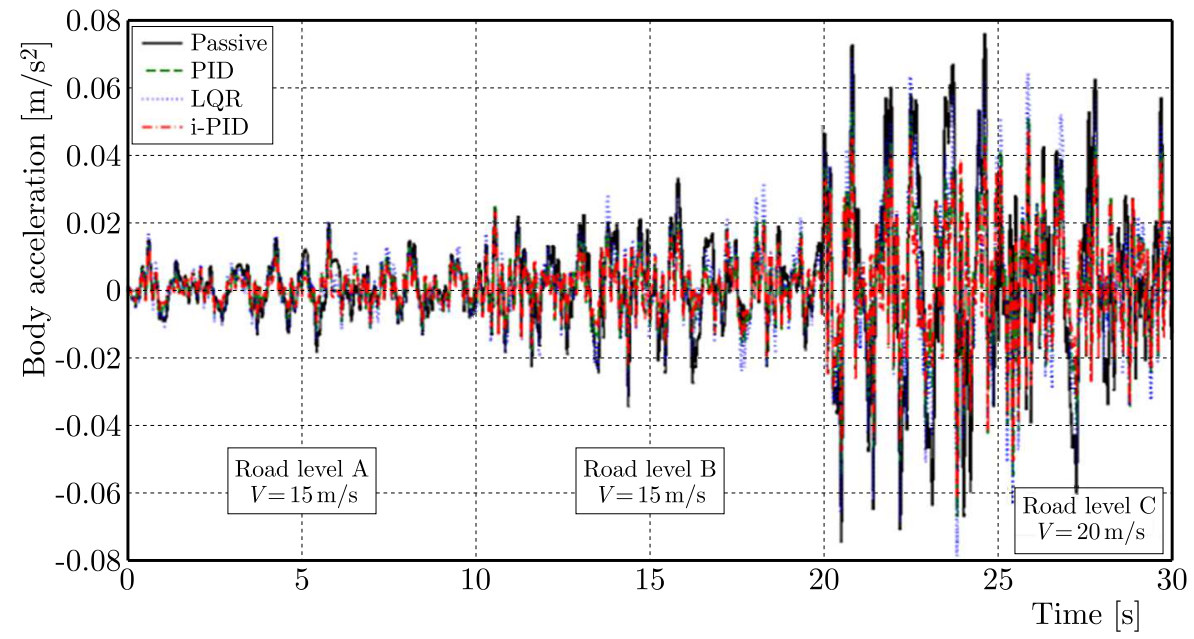

Fig. 11. Effect of vehicle speed and road roughness variation on ride comfort

Table 4 . The RMS with road pavement variation and speed variation

\begin{tabular}{|c|c|c|c|c|}
\hline$\chi_{R M S}=\frac{\|\chi\|}{n} \sqrt{\frac{1}{n} \sum_{i=1}^{n} \chi_{i}^{2}}$ & Passive & PID & LQR & i-PID \\
\hline \hline Road class A $(V=15 \mathrm{~m} / \mathrm{s})$ & 0.0060 & 0.0045 & 0.0058 & 0.0038 \\
\hline Road Class B $(V=15 \mathrm{~m} / \mathrm{s})$ & $0.0121(\uparrow 50 \%)$ & $0.0089(\uparrow 49 \%)$ & $0.0116(\uparrow 50 \%)$ & $0.0066(\uparrow 42 \%)$ \\
\hline Road class C $(V=20 \mathrm{~m} / \mathrm{s})$ & $0.0305(\uparrow 80 \%)$ & $0.0233(\uparrow 80 \%)$ & $0.0297(\uparrow 80 \%)$ & $0.0201(\uparrow 62 \%)$ \\
\hline
\end{tabular}


structure is not ineffective. The attenuation of oscillation requires the use of a low pass filter in the case of PID and LQR. However, the low pass filters of the algebraic estimator in i-PID are able to attenuate the effect of noise more that PID and LQR.

\subsection{Effect of nonlinearities}

In the presence of nonlinearities and disturbance inputs, the required suspension properties degrade (Rath et al., 2015). For example, a replication of suspension deflection can be achieved by cubic spring characteristics. In fact, a proposition to show the effectiveness of the i-PID controller to reject this kind of problems and to guarantee the best ride comfort is shown below. This scenario is tested when the half car system is subjected to a bump input. The effectiveness is verified by comparison between RMS values of the linear and nonlinear case. The nonlinear spring and damper force can be defined as follows

$$
\begin{aligned}
& F_{\text {spring }, i}(t)=k_{s, i}\left(z_{s, i}-z_{u, i}\right)+k_{n s, i}\left(z_{s, i}-z_{u, i}\right)^{3} \\
& F_{\text {damper }, i}(t)=d_{s, i}\left(z_{s, i}-z_{u, i}\right)+d_{n s, i} \sqrt{\left|z_{s, i}-z_{u, i}\right|} \operatorname{sgn}\left(z_{s, i}-z_{u, i}\right)
\end{aligned}
$$

where $k_{n s, i}=2.35 \cdot 10^{6} \mathrm{~N} / \mathrm{m}$ and $d_{n s, i}=400 \mathrm{Ns} / \mathrm{m}$ (Ekoru and Pedro, 2013).

The results depicted in Fig. 12, demonstrate that i-PID maintains its robustness and gives the best required ride comfort with slight amplification. Furthermore, the required performances are not degraded. However, there exists an increase of RMS values in the case of LQR and PID. Generally speaking, the cancelling term in the i-PID equation demonstrates the ability of the intelligent controller to perform well with nonlinear system and is able to deal with changes without recalibration of controller parameters.

(a)

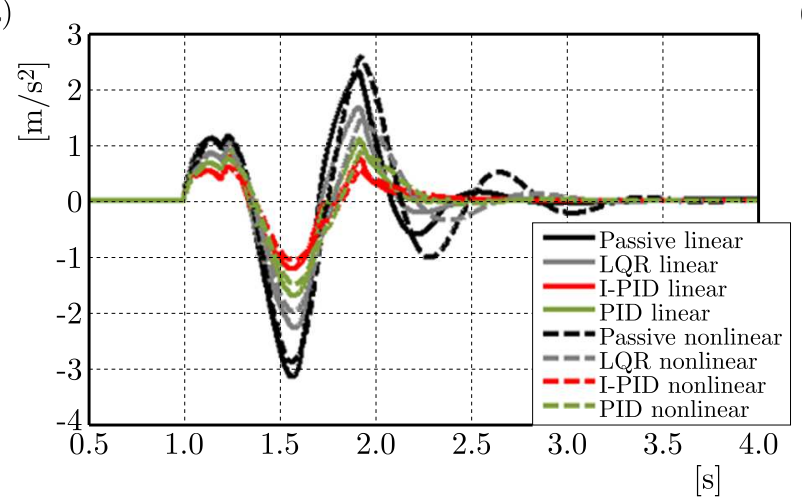

(b)

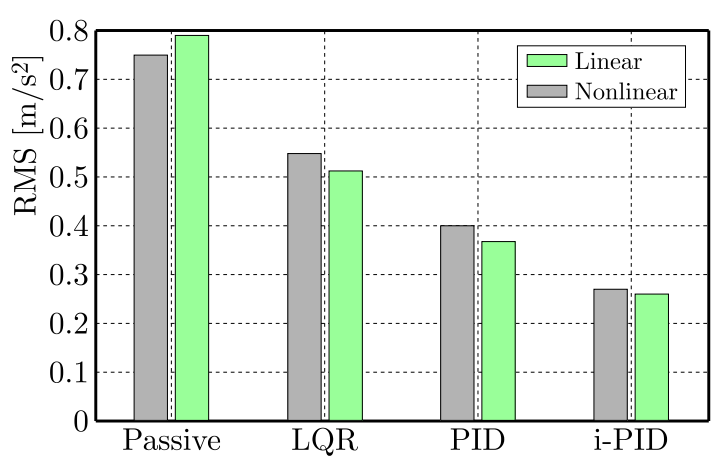

Fig. 12. Effect of nonlinearities on ride comfort

\section{Conclusion}

This paper investigated a "Multi-Input-Multi-Output Model Free Control" as a new technique of control for active half car systems. The proposed controller is established on a classical PID concept as an online compensator that is able to avoid the need of precise information about the model. Furthermore, the superiority is highlighted by avoiding different kinds of perturbations with an online calibration of scaling parameters. As presented by numerical results, the i-PID controller is able to improve the required performances such as ride comfort, road holding and rattle space performance compared to traditional controllers in the frequency band range [0$20] \mathrm{Hz}$. Moreover, the implementation requires only two sensors (accelerations are measured on the left and right corner of the upper mass) and can be achieved by low cost instruments. The robustness to parameter variation is better ensured by the i-PID controller under variation of 
the sprung mass, vehicle speed and nonlinearities. In fact, the recalibration process of tuning parameters is online. Besides, this intelligent scheme allows one to reduce the actuator force compared to PID. Future studies will focus on experimental validation of the obtained results.

\section{References}

1. Demir O., Keskin I., Cetin S., 2012, Modeling and control of a nonlinear half-vehicle suspension system: a hybrid fuzzy logic approach, Nonlinear Dynamics, 67, 3, 2139-2151

2. Ekoru J.E., Pedro J.O., 2013, Proportional-integral-derivative control of nonlinear half-car electro-hydraulic suspension systems, Journal of Zhejiang University Science A, 14, 6, 401-416

3. FAris W.F., IhSAn S.I., Ahmadian M., 2009, Transient and steady state dynamic analysis of passive and semi-active suspension systems using half-car model, International Journal of Modelling, Identification and Control, 6, 1, 62-71

4. Ferdek U., ŁUCZKo J., 2015, Performance comparison of active and semi-active SMC and LQR regulators in a quarter-car model, Journal of Theoretical and Applied Mechanics, 53, 4, 811-822

5. Fuiess M., Join C., 2013, Model-free control, International Journal of Control, 86, 2228-2252

6. Haddar M., Baslamisli S.C., Chaari R., Chaari F., Haddar M., 2019a, Road profile identification with an algebraic estimator, Proceedings of the Institution of Mechanical Engineers, Part C: Journal of Mechanical Engineering Science, 233, 4, 1139-1155

7. Haddar M., Baslamisli S.C., ChaAri F., Haddar M., 2017, On-line adaptive scaling parameter in active disturbance rejection controller, [In:] Rotating Machinery and Signal Processing, A. Felkaoui, F. Chaari, M. Haddar (Edit.), pp. 79-86, Springer, Cham, DOI: 10.1007/978-3-31996181-1_7

8. Haddar M., ChaAri R., Baslamisli S.C., ChaAri F., Haddar M., 2019b, Intelligent PD controller design for active suspension system based on robust model-free control strategy, Proceedings of the Institution of Mechanical Engineers, Part C: Journal of Mechanical Engineering Science, DOI: $10.1177 / 0954406219836443$

9. Hasbullah F., Faris W.F., 2017, Simulation of disturbance rejection control of half-car active suspension system using active disturbance rejection control with decoupling transformation, Journal of Physics, Conference Series, 949, 1, 012025

10. Hasbullah F., Faris W.F., Darsivan F.J., 2015, Ride comfort performance of a vehicle using active suspension system with active disturbance rejection control, International Journal of Vehicle Noise and Vibration, 11, 78-101, DOI: 10.1504/IJVNV.2015.067995

11. Hua C., Chen J., Li Y., Li L., 2018, Adaptive prescribed performance control of half-car active suspension system with unknown dead-zone input, Mechanical Systems and Signal Processing, 111, 135-148, DOI: 10.1016/j.ymssp.2018.03.048

12. ISO 2631-1:1997, Evaluation of human exposure to whole-body vibration - Part 1: General requirements

13. ISO 8608: Mechanical Vibration-Road Surface Profiles-Reporting of Measured Data, International Standardization Organization, Geneva, Switzerland, 199

14. León-Vargas F., Garelli F., Zapateiro M., 2018, Limiting vertical acceleration for ride comfort in active suspension systems, Proceedings of the Institution of Mechanical Engineers, Part I: Journal of Systems and Control Engineering, 232, 3, 223-232

15. Łuczko J., Ferdek U., 2016, Continuous and discrete sliding mode control of an active car suspension system, Journal of Theoretical and Applied Mechanics, 54, 3-11

16. Maciejewski I., Krzyżyński T., Pecolt S., Chamera S., 2019, Semi-active vibration control of horizontal seat suspension by using magneto-rheological damper, Journal of Theoretical and Applied Mechanics, 57, 2, 411-420 
17. Pan H., Sun W., Gao H., Hayat T., Alsaadi F., 2015, Nonlinear tracking control based on extended state observer for vehicle active suspensions with performance constraints, Mechatronics, 30, 363-370, DOI: 10.1016/j.mechatronics.2014.07.006

18. Phu D.X., Huy T.D, Mien V., Choi S.B., 2018, A new composite adaptive controller featuring the neural network and prescribed sliding surface with application to vibration control, Mechanical Systems and Signal Processing, 107, 409-428, DOI: 10.1016/j.ymssp.2018.01.040

19. Pusadkar U.S., Chaudhari S.D., Shendge P.D., Phadke S.B., 2019, Linear disturbance observer based sliding mode control for active suspension systems with non-ideal actuator, Journal of Sound and Vibration, 442, 428-444, DOI: 10.1016/j.jsv.2018.11.003

20. Rajamani R., 2011, Vehicle Dynamics and Control, Springer Science \& Business Media

21. Rath J.J., Veluvolu K.C., Defoort M., 2015, Simultaneous estimation of road profile and tire road friction for automotive vehicle, IEEE Transactions on Vehicular Technology, 64, 10, 4461-4471

22. Senthil Kumar P., Sivakumar K., Kanagarajan R., Kuberan S., 2018, Adaptive Neuro Fuzzy Inference System control of active suspension system with actuator dynamics, Journal of Vibroengineering, 20, 1, 541-549, DOI: 10.21595/jve.2017.18379

23. Wakeham K.J., Rideout D.G., 2011, Model complexity requirements in design of half car active suspension controllers, [In:] ASME 2011 Dynamic Systems and Control Conference and Bath/ASME Symposium on Fluid Power and Motion Control, Virginia

24. Wang H.P., Mustafa G.I., Tian Y., 2018, Model-free fractional-order sliding mode control for an active vehicle suspension system, Advances in Engineering Software, 115, 452-461, DOI: 10.1016/j.advengsoft.2017.11.001

25. Wang J., Jin F., Zhou L., Li P., 2019, Implementation of model-free motion control for active suspension systems, Mechanical Systems and Signal Processing, 119, 589-602 